\title{
EFFECT OF MEMORY TRAINING PROGRAM ON NURSING TEACHING STAFF'S PERFORMANCE AT THE FACULTY OF NURSING
}

\author{
Eman Shokry Abd Allah ${ }^{1}$, Nashwa Ahmed Hussein ${ }^{2}$, Shadia Fathy \\ Mahmoud $^{3}$ \\ ${ }^{1}$ Gerentological Nursing, Faculty of Nursing, Zagazig University, Egypt \\ ${ }^{2}$ Psychiatric and Mental Health Nursing, Faculty of Nursing, Zagazig University, Egypt \\ ${ }^{3}$ Psychiatric and Mental Health nursing, Faculty of Nursing, Zagazig University, Egypt \\ Email of Corresponding author: nashwaahmed34@yahoo.com
}

\begin{abstract}
Aim: The aim of study was to evaluate the effect of the memory training program on nursing teaching staff's performance at the Faculty of Nursing. Design: A quasiexperimental design was used in this study. Methods: Pre- post assessment of outcome was used in this study. Setting: The study was conducted in the Faculty of Nursing, Zagazig University, Egypt. Sample: 45 nursing teaching staff who worked in the previous mentioned setting were included in this program. The intervention program consisted of theoretical and practical parts about memory and performance implemented through 14 sessions, and lasted for two months. Tools included sections for Socio-demographic data sheet, Memory assessment clinics-self rating scale and Performance scale. Results: of the present study showed that the memory training program has a significant effect on performance .There was an improvement of memory after the memory training program between pre and post-test. Conclusion: It was concluded that the training program achieved its objectives in enhancing the nursing teaching staff's memory and that this training program has a significant effect on performance. Recommendation, It was recommended that conducting an annual course for all nursing teaching staff to enhance the memory in the form of conferences, seminars and workshops.
\end{abstract}

Key words: Memory Training Program, Nursing Teaching Staff, Performance

\section{Introduction:}

Memory is the process of retaining information over time and the ability to use the past experiences in order to determine the future path. Memory is essential in everyday life. The person would not be able to function in the present or move forward without relying on memory (Ann, 2014).

Nurse educators are employed in academic institutions and a variety of health care agencies. They educate students in all the levels, and in health care agencies they are responsible for providing nurses and other health care professionals continuing education and training (Oermann, 2015).
Performance is the accomplishment of a task in accordance with standards of accuracy, completeness, and efficiency. Many business personnel directors assess the job performance of each employee on an annual or quarterly basis in order to help them identify suggested areas for improvement (Hrcouncil.ca, 2013).

For employees, having a more efficient memory translates to better job performance which can positively impact the chances of advancing the career in a company. A better memory will allow to manage every aspect of their business more easily and allow to remember even the small details (Helpguide.org, 2014). 
Significance of the Study

Few studies have investigated the benefits of memory training for healthy adults. Research has shown that healthy adults can improve memory skills with instruction and practice and that booster training facilitates long-term remembering. Memory training programs can have significant benefits which can extend beyond the trained task and lead to significant changes in both behavior and brain function. Hussein, (2013) who assessed Nursing Teaching Staff's Memory and its relation to their Performance, Achievement Motivation and Meaning of Life in Zagazig University showed that there was a highly positive statistical significant correlation between memory and performance: three fifths of the studied sample had fair memory problems and more than half of the studied sample who had job stressors had a fair subjective memory. So this research will evaluate the effect of memory training program on the nursing teaching staff's performance at the faculty of nursing.

\section{Aim of the study:}

The aim of the study was to evaluate the effect of the memory training program on nursing teaching staff's performance at the Faculty of Nursing

\section{Objectives:}

1- Assess the memory and performance of the nursing teaching staff

2- Develop the memory training program (Its design, content and schedule).

3- Implement the memory training program for the nursing teaching staff

4-Evaluate the effectiveness of memory training program for the nursing

\section{Sample and Methods:}

Design:

A quasi experimental design was conducted to achieve the aim of the study.

\section{Setting:}

The study was conducted at the Faculty of Nursing, Zagazig University, Egypt.

\section{Participants:}

A purposive sample included nursing teaching staff who worked in the previous mentioned setting was recruited for this study. These subjects were met the following criteria: gender, the educational level and the different age groups. Actual number of nursing teaching staff during data collection was $(n=106)$.Nursing teaching staff who agree to participate in the study during pretest was $(n=77)$.Number of nursing teaching staff who have moderate and sever memory was $(\mathrm{n}=58)$ who actually have memory problems. Number of nursing teaching staff who agree to participate in memory program and post-test was $(n=45)$.

\section{Research tools:}

1. Socio-demographic data of nursing teaching staff (pre/post-test) It included information about the nursing teaching staff like the age, gender, residence, department, position, marital status, number of children, number of years of teaching experience and income.

2. Memory assessment clinics-self rating scale (MAC-S) (pre/post-test) designed and revised by (Winterling et al., 1986(.This scale evaluated one's insight into one's own memory function. It consists of 49 items divided into three specific factors, namely the memory ability (22 items), frequency of memory problems(24 items) and global memory ability in various situations(3 items). It is measured on 5-point likert scale. It has high test-retest reliability and concurrent validity by (Crook\& Larrebea, 1992) with correlation ranging from .88 to .92 on memory ability, from .90 to .93 on frequency and .45 to .85 on the global scores. High scores on the scales indicate a good subjective memory and low scores indicate a poor subjective memory. Scoring system of memory 
EFFECT OF MEMORY TRAINING PROGRAM ON NURSING etc...

scale poor subjective memory (1$<147)$,fair subjective memory (147$<183.5)$ and good subjective memory (183.5-245)

3. Performance scale:(pre/post-test) This scale was constructed by the researcher and validated by five experts in the Psychiatric and Mental Health Nursing Department in Cairo University according to current related literature based on quality standards. It composed of 75 items. Each of the nursing teaching staff measured the performance by using (self-rating scale).This scale includes seven competencies (planning (4 items), cognitive competencies (7 items), personal competencies (9 items), professional competencies (38 items), professional development (6 items), productivity (5 items and activities \&projects (6 items). Each of these competencies has specific performance standards. Each of these standards was measured by specific performance indicators. The scale items were rated on four point likert scale with response options of always (3), often (2), sometimes (1) and rarely (0). High scores indicate high performance. Scoring System of performance scale low $(0-<135)$, middle $(135-<168)$ and high (168225).

Content validity and reliability: Once the tools were prepared, their face and content validity were ascertained by a panel of five experts in psychiatric and mental health nursing, who revised the tools for clarity, relevance, applicability, comprehensiveness, and ease of implementation. The reliability of the Memory assessment clinics-self rating scale (MAC-S) was assessed in the present study, showing excellent reliability with a Cronbach's alpha coefficient $(\mathrm{r}=.957)$, and
Performance scale showing excellent reliability with a Cronbach's alpha coefficient $(r=.967)$.

\section{Description of the intervention:}

1-Assessment Phase (pre-intervention data collection)

The researcher attend many courses to be qualified to design \& apply memory training program to nursing teaching staff and to be certified as memory trainer.

The average time to fill in all the tools including socio-demographic data sheet, performance scale and memory assessment clinics-self rating scale which was thirty to forty five minutes. Filling in the sociodemographic data sheet took five minutes, while the memory assessment clinics-self rating scale took fifteen minutes and the performance scale took ten minutes. This technique was repeated for each nursing teaching staff included in the study. After data collection, the researcher and a specialist in statistics carried out all necessary steps for checking completeness of data and proceeded to the scoring of the members' answers.

Then, they obtained a list of the names of nursing teaching staff from College Administration Department, an official permission from the Dean of the Faculty of Nursing for the approval of conducting the study and getting access to nursing teaching staff's list of names from the College Administration Department.

The researcher started by introducing herself to the nursing teaching staff and explained briefly the aim of the study and reassured that the information obtained is strictly confidential and would not be used for any purposes other than research. The researcher clarified the method of filling in the tools. Sometimes, the nurse needed clarifications for the questions; therefore, the researcher answered without any judgmental words or changing the meaning of the questions. Time consumed for answering the study tools ranged from 30-45 minutes for each 
nursing teaching staff from 9am to $3 \mathrm{pm}$. This phase lasted for two months. The time in which the data were collected was from the beginning of September 2015 to the end of November 2015.

\section{2-Planning phase}

Based on the results, a specialist in statistics classified nursing teaching staff into good, moderate and fair subjective memory. This phase started from the beginning of December 2015 to the end of December 2015.

Then the researcher designed the training program contents according to the identified nursing teaching staff's needs. The program's content was also based on reviewing the related literature.

The identified needs, requirements and gaps were translated into the aim and objectives of the training program. The program was written in a simple English language. It consisted of two main parts. The first theoretical part included knowledge about memory such as definition, significance, process, stages, types of long term memory, marks of good memory \& memory improvement principles and how to optimize the body and mind (sleep, diet, exercise, biorhythms and relaxation techniques). The second practical part included training about memory techniques that enhance right \& left brain and techniques that enhance remembering names, numbers and lists.

The program was judged by three faculty members (Professor of Psychiatric and Mental Health Nursing -Ain Shams University, Professor of psychology Faculty of Arts - Zagazig University \& Assistant Professor of Psychiatric Medicine Faculty of Medicine - Zagazig University) and edited by Professor of English Faculty of Arts - Zagazig University) and the amendments were made based on the comments. This phase took from the beginning of January 2016 to the end of September 2016.

\section{3- Implementation phase:}

The program's contents were implemented in the form of sessions. The length of each session ranged from thirty to forty five minutes. The nursing teaching staff were being divided into seven groups according to the department, meeting individually or in groups. The sessions were administered twice/week for each study group. The total number of sessions was fourteen sessions for each group. These sessions were held each day from nine am to three pm according to the time allowed for each department. This phase lasted for seven weeks. This phase lasted for two months for the beginning of October 2016 to the end of December 2016.

To ensure that nursing teaching staff understand the program content, each session started with a summary about what was given through the previous session, followed by the objectives of the new one, taking into consideration the use of language to suit the educational level of nursing teaching staff, the response, the time available, and the content for each session. Motivation and reinforcement techniques, such as praise recognition during the session, were used to enhance learning. Different methods of teaching were used such as lectures, group discussions and role playing. Suitable teaching aids were prepared and used during the program implementation such as pictures and software applications. To ensure equal exposure of all nursing teaching staff to the same content and learning experiences, the same teaching methods, discussions and same handouts were used.

The researcher made software about memory training program in the form of one to fourteen numbers, each number hyperlink to the contents introduced during the sessions in the form of word documents, videos, software applications used during the sessions. In addition to this 
the researcher made a group on a Facebook namely (Memory Clinic) that concerned with listing memory techniques that have done during sessions. The researcher spent a month from the beginning of January 2017 to the end of January 2017.

\section{Program sessions:}

Session 1 (Time: 30-45):

During the initial session, the researcher explained the purpose of the program, instructions followed by the exercises, the place of meeting, the timetable that was twice/week for each study group and information about the booklet that would be delivered after sessions to add any information recommended.

Session 2 (Time: 30-45 (:

The focus of this session was providing an overview about memory such as definition, significance, types, and stages; types of the long-term memory, the marks of good memory and the memory improvement principles.

Session 3 (Time: 30-45):

The focus of this session was providing knowledge and training skills related to how to optimize the body and mind (having a positive outlook and destressing routines (progressive muscle relaxation, yoga, meditation and acupuncture). First, the researcher provided an overview description for each technique, then the researcher prepared some relaxation techniques and did these techniques in front of the nursing teaching staff and began to imitate the researcher. Session 4 (Time: 30-45(:

The focus of this session was providing knowledge and training skills related to how to optimize the body and mind (sleeping well, eating well, making physical exercise and being aware of biorhythms). First, the researcher provided an overview description for each technique, then the researcher prepared some strategies and did these strategies in front of the nursing teaching staff, after which the nursing teaching staff began to imitate the researcher.

\section{Session 5 (Time: 30-45):}

The focus of this session was providing knowledge and training skills about memory techniques that enhance left brain (concentration classification and memory pegs). First, the researcher provided an overview description for each technique, then the researcher prepared training skills for each technique and the nursing teaching staff followed the instructions for each skill .

Session 6 (Time: 30-45) :

The focus of this session was providing knowledge and training skills about memory techniques that enhance right brain (visualization, organization and linking). First, the researcher provided an overview description for each technique, then the researcher prepared training skills for each technique and the nursing teaching staff followed the instructions for each skill .

\section{Session 7 (Time: 30-45):}

The focus of this session was providing knowledge and training skills about techniques that enhance names and faces (The 3-step memory booster, Dominic O'Brien's strategy and Harry Lorayne's strategy, Chester Santos' strategy). First, the researcher provided an overview description for each technique, then the researcher prepared training skills for each technique and the nursing teaching staff followed the instructions for each skill .

Session 8 (Time: 30-45):

The focus of this session was providing knowledge and training skills about techniques that enhance numbers (the number-association system and the chunking method). First, the researcher provided an overview description for each technique, then the researcher prepared training skills for each technique and the 
nursing teaching staff followed the instructions for each skill .

Session 9 (Time: 30-45):

The focus of this session was providing knowledge and training skills about memory techniques that enhance lists (first letter association, image system strategy and rhyme strategy). First, the researcher provided an overview description for each technique, then the researcher prepared training skills for each technique and the nursing teaching staff followed the instructions for each skill.

Session 10 (Time: 30-45):

The focus of this session was providing knowledge and training skills about memory techniques that enhance lists and extensive amount of information (the journey method, body parts and mind map). First, the researcher provided an overview description for each technique, then the researcher prepared training skills for each technique and the nursing teaching staff followed the instructions for each skill .

Session 11 (Time: 30-45):

The focus of this session was providing knowledge and training skills about techniques that enhance human performance (general strategies enhance general performance, planning and personal competencies). First, the researcher provided an overview description for each technique, then the researcher prepared training skills for each technique and did these techniques in front of the nursing teaching staff and began to imitate the researcher.

Session 12 (Time: 30-45):

The focus of this session was providing knowledge and training skills about techniques that enhance human performance (strategies enhance professional competencies, professional development, productivity and activities \&projects). First, the researcher provided an overview description for each technique, then the researcher prepared training skills for each technique and did these techniques in front of the nursing teaching staff, and began to imitate the researcher .

\section{Session 13 (Time: 30-45):}

The focus of this session was to review the objectives of the program and summarize what has been taught during the sessions by using software applications (free and easy biorhythm calculator, mind map application, memory clinic, mind genius, super memory, efficient reminder, tasty food memory). The researcher prepared each software for all nursing teaching staff and taught them how to use these applications.

Session 14 (Time: 30-45):

This session was a termination of the training program sessions for nursing teaching staff and for post assessment. The researcher acknowledged the nursing teaching staff's role.

\section{4-Evaluation phase:}

The evaluation of the training program sessions was done immediately after its implementation by comparing the change of memory and evaluating its effect on performance through applying the same tool of pre- intervention.

\section{Pilot study:}

A pilot study for tools of data collection was carried out on 11 nursing teaching staff within selected criteria in order to test for clarity, relevance, comprehensiveness, understandable, feasible, applicability and ease for implementation. Nursing teaching staff who shared in the pilot study were included from the main study sample.

\section{Ethical considerations:}

All ethical issues were taken into consideration during all phases of the study. The ethical research considerations in this study included the following: the objectives and the aims of the study were explained to the participants, the researcher confirmed the confidentiality of participants, and participants were allowed to choose to participate or not and they had 
the right to withdraw from the study at any time without penalty.

\section{Statistical analysis:}

All collected data were organized, categorized, tabulated, entered, and analyzed by using SPSS (Statistical Package for Social Sciences); a software program version 20 , which was applied to frequency tables and statistical significance. Associations were assessed by using Monte Carlo exact test and Marginal homogeneity test.

\section{Results:}

Table 1: revealed that there was a highly statistically significant difference between pre/post training program regarding memory ability, memory problems, global memory and memory total $(\mathrm{p}=0.001)^{*}$.

Table 2: After application of posttest, shows that $95.7 \%$ of the studied sample who aged less than 30 have a good subjective memory. Regarding the department, $100 \%$ of the studied sample (Medical and Surgical Nursing Department, Gerentological Nursing Department, Psychiatric and Mental Health Nursing Department, Obstetric and Gynecological Nursing Department, Nursing Administration Department, Pediatric Nursing Department) had a good subjective memory. Table (2) demonstrates that there is a significant relation between memory and department $(\mathrm{p}=0.013 *)$.Concerning the years of experience, $93.7 \%$ of the studied sample who have 6-10 years of experience had a good subjective memory. The table (2) also demonstrated that $94.1 \%$ of the studied sample who were demonstrators had a good subjective memory. $94.4 \%$ of the studied sample were married had a good subjective memory. $95.7 \%$ of the studied sample who had 1-2 children had a good subjective memory, and $94.7 \%$ of the studied sample who have an average income of $2000 \mathrm{p}$ and $5000 \mathrm{p}$ or more had a good subjective memory.
Table 3: After application of posttest, explained that $91.3 \%$ of the studied sample who were less than thirty years, had a high performance. $85.7 \%$ of the studied sample who were females, had a high performance. Regarding department, $100 \%$ of the studied sample (Psychiatric and Mental Health Nursing Department, Community Health Nursing Department, Nursing Administration Department), had a high performance. Concerning the years of experience, $100 \%$ of the studied sample with one to five years of experience, had a high performance. There was a significant relation between performance and years of experience $\left(\mathrm{p}=.027^{*}\right)$. The table also stated that $100 \%$ of the studied sample who were assistant professor and demonstrators, had a high performance. There was a significant relation between performance and position $(\mathrm{p}=.049)$. $83.3 \%$ of the studied sample who are married had a high performance. $82.6 \%$ of the studied sample, who have one to two children, had a high performance. $100 \%$ of the studied sample, who had an average income of 2000 pounds, had a high performance. There was a significant relation between performance and average income $\left(\mathrm{p}=.046^{*}\right)$.

Table 4: showed that there was a statistically significant positive correlation between memory and performance $\left(\mathrm{p}=.047^{*}\right)$ after post-test intervention.

\section{Discussion:}

The aim of the study was to evaluate the effect of memory training program on the nursing teaching staff's performance at the Faculty of Nursing.

In terms of memory among nursing teaching staff, the current study stated that there was a highly statistically significant difference between pre/post training program regarding total memory $\left(\mathrm{p}=(0.001)^{*}\right.$. This might be because the groups were small, the time of sessions was suitable for each nursing teaching staff, all of them were interested in the 
topic and apply the memory training program in the work and at home by using memory software.

As regards performance of the nursing teaching staff, the current study showed that more than two thirds of the studied sample, have a high performance after post-test. This might be due to the fact that the nursing teaching staff were more involved in research, publication, communication activities, and professional organization affiliation.

Concerning performance and years of experience, the current study showed that there was a positive relation between performance and years of experience $(\mathbf{p}=\mathbf{. 0 2 7} *)$. These might be due to the fact that when they become older, they become more experienced and learn more from their faults. Nursing teaching staff with high years of experience were reported to participate more in professional development activities, suggesting that continue learning, attain licenses and actively improve the nursing skills. With high years of experience, they become person -oriented and not job or company oriented. This, therefore, goes to show that people who have stayed for a long time in the job are not likely to make mistakes like the new nursing teaching staff, so perform better.

As regards memory and performance, the findings of the present study indicated that memory had a positive statistically significant correlation with performance $(\mathbf{0 . 0 4 7})$. Few studies have investigated the correlation between memory and performance. This finding suggested that having a better memory increases the ability to learn and retain information, and that it makes the person more productive at work, feeling more competent around handling the things that needed to be done day by day and being more tractable to the other people in life .

In the same way, Chiu, (2011) assessed the Transactive Memory System impacts on the team performance throughout knowledge quality and perceived knowledge satisfaction in China. TMS serves as one important means to enhance both teamwork process and project team performance. This finding concluded that having a mature TMS can effectively enhance performance directly and indirectly through improving communication and coordination process. Moreover, Pottage et al., (2012) investigated visual attention and emotional memory. The recall of aversive pictures is partially mediated by concurrent task performance in Malaysia revealed that concurrent task performance significantly mediated the emotional enhancement of memory under divided attention.

Similarly, Zinke et al., (2014) who investigated working memory training and transfer in older adults: effects of age, baseline performance, and training gains revealed significant training effects in all 3 training tasks in trained participants relative to controls, as well as near transfer to a verbal working memory task and transfer to a performance task. These findings suggest that cognitive plasticity is preserved over a large range of old age and that even a rather short training regime can lead to (partly specific) training and transfer effects.

\section{Conclusion:}

In the light of the main study findings, it could be concluded that the training program achieved its objectives in enhancing the nursing teaching staff's memory, and this training program has a significant effect on performance.

\section{Recommendations:}

It was recommended conducting a training program and an annual course for all nursing teaching staff to enhance the memory in the form of conferences, seminars and workshops and providing guidance or handbook for memory training program. 
EFFECT OF MEMORY TRAINING PROGRAM ON NURSING etc...

$\overline{\text { Acknowledgement }}$

This study supported by Prof. Dr. Eman

Shokry Abd Allah, A professor and Head of Gerentological Nursing Department, Faculty of Nursing Zagazig University, for honest assistance, continuous advises and critical remarks. I am also hugely appreciative to my supervisor Dr. Shadia
Fathy Mahmoud, a lecturer of Psychiatric and Mental Health Nursing, Faculty of Nursing, Zagazig University, for invaluable advices and supervision in the initial stages of this study. Last but not least, I acknowledge and thank all the Nursing Teaching Staff who participated in this study for help and cooperation.

Table 1: Comparison of memory among nursing teaching staff at pre/post training intervention

\begin{tabular}{|c|c|c|c|c|c|c|}
\hline \multirow{3}{*}{\multicolumn{2}{|c|}{ Memory assessment }} & \multicolumn{4}{|c|}{ Phase } & \multirow{3}{*}{ MH (P) } \\
\hline & & \multicolumn{2}{|c|}{$\begin{array}{c}\text { Pre } \\
\text { intervention }(n=45)\end{array}$} & \multicolumn{2}{|c|}{$\begin{array}{c}\text { Post } \\
\text { intervention }(n=45)\end{array}$} & \\
\hline & & No & $\%$ & No & $\%$ & \\
\hline \multirow{3}{*}{ Memory ability } & Low & 16 & $35.6 \%$ & 0 & $0.0 \%$ & \multirow{3}{*}{$\begin{array}{l}12.9 \\
(0.001)^{*} *\end{array}$} \\
\hline & Fair & 21 & $46.7 \%$ & 0 & $0.0 \%$ & \\
\hline & High & 8 & $17.7 \%$ & 45 & $100.0 \%$ & \\
\hline \multirow{3}{*}{$\begin{array}{l}\text { Memory } \\
\text { problems }\end{array}$} & Low & 15 & $33.3 \%$ & 31 & $68.9 \%$ & \multirow{3}{*}{$\begin{array}{l}10.3 \\
(0.001) * *\end{array}$} \\
\hline & Fair & 21 & $46.7 \%$ & 14 & $31.1 \%$ & \\
\hline & High & 9 & $20 \%$ & 0 & $0.0 \%$ & \\
\hline \multirow{3}{*}{$\begin{array}{l}\text { Global } \\
\text { memory }\end{array}$} & Low & 18 & $40.0 \%$ & 0 & $0.0 \%$ & \multirow{3}{*}{$\begin{array}{l}10.0 \\
(0.001) * *\end{array}$} \\
\hline & Fair & 22 & $48.9 \%$ & 12 & $26.7 \%$ & \\
\hline & High & 5 & $11.1 \%$ & 33 & $73.3 \%$ & \\
\hline \multirow{3}{*}{ Memory total } & $\begin{array}{l}\text { Poor subjective } \\
\text { memory }\end{array}$ & 20 & $44.4 \%$ & 0 & $0.0 \%$ & \multirow{3}{*}{$\begin{array}{l}13.7 \\
(0.001) * *\end{array}$} \\
\hline & $\begin{array}{l}\text { Fair subjective } \\
\text { memory }\end{array}$ & 25 & $55.6 \%$ & 3 & $6.7 \%$ & \\
\hline & $\begin{array}{l}\text { Good subjective } \\
\text { memory }\end{array}$ & 0 & $0.0 \%$ & 42 & $93.3 \%$ & \\
\hline
\end{tabular}

MH:Marginal Homogeneity test $* \mathrm{P}<0.05$ (significant) $\quad * * \mathrm{P}<0.01$ (highly significant) 
Eman Shokry Abd Allah et. al.

Table 2: Relation between socio-demographic characteristics of the studied sample and memory (phase two posttest $n=45$ )

\begin{tabular}{|c|c|c|c|c|c|c|}
\hline \multirow{3}{*}{\multicolumn{2}{|c|}{ Demographic data }} & \multicolumn{4}{|c|}{ 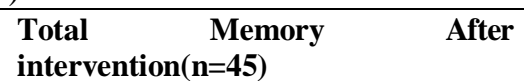 } & \multirow{3}{*}{$M C P$} \\
\hline & & \multicolumn{2}{|c|}{$\begin{array}{l}\text { Fair subjective } \\
\text { memory }\end{array}$} & \multicolumn{2}{|c|}{$\begin{array}{l}\text { Good subjective } \\
\text { memory }\end{array}$} & \\
\hline & & No & $\%$ & No & $\%$ & \\
\hline \multirow{4}{*}{ Age } & $<30$ & 1 & $4.3 \%$ & 22 & $95.7 \%$ & \multirow{4}{*}{0.788} \\
\hline & $30-$ & 2 & $11.1 \%$ & 16 & $88.9 \%$ & \\
\hline & $40-$ & 0 & $0.0 \%$ & 3 & $100.0 \%$ & \\
\hline & $50+$ & 0 & $0.0 \%$ & 1 & $100.0 \%$ & \\
\hline \multirow{2}{*}{ Gender } & Male & 0 & $0.0 \%$ & 3 & $100.0 \%$ & \multirow{2}{*}{0.632} \\
\hline & Female & 3 & $7.1 \%$ & 39 & $92.9 \%$ & \\
\hline \multirow{7}{*}{ Department } & $\begin{array}{l}\text { Medical and Surgical } \\
\text { Nursing }\end{array}$ & 0 & $0.0 \%$ & 11 & $100.0 \%$ & \multirow{7}{*}{$0.013^{*}$} \\
\hline & $\begin{array}{l}\text { Obstetric and } \\
\text { Gynecological Nursing }\end{array}$ & 0 & $0.0 \%$ & 11 & $100.0 \%$ & \\
\hline & Pediatric Nursing & 0 & $0.0 \%$ & 3 & $100 \%$ & \\
\hline & Nursing Administration & 0 & $0.0 \%$ & 4 & $100.0 \%$ & \\
\hline & Community Health & 1 & $50.0 \%$ & 1 & $50.0 \%$ & \\
\hline & $\begin{array}{l}\text { Psychiatric and Mental } \\
\text { Health Nursing }\end{array}$ & 0 & $0.0 \%$ & 11 & $100.0 \%$ & \\
\hline & Gerontological Nursing & 0 & $0.0 \%$ & 3 & $100.0 \%$ & \\
\hline \multirow{5}{*}{$\begin{array}{l}\text { Years of } \\
\text { experience in } \\
\text { your faculty }\end{array}$} & $<1$ year & 1 & $33.3 \%$ & 2 & $66.7 \%$ & \multirow{5}{*}{0.313} \\
\hline & $1-$ & 0 & $0.0 \%$ & 14 & $100.0 \%$ & \\
\hline & $6-$ & 1 & $6.3 \%$ & 15 & $93.7 \%$ & \\
\hline & $11-$ & 1 & $10.0 \%$ & 9 & $90.0 \%$ & \\
\hline & $26-$ & 0 & $0.0 \%$ & 2 & $100.0 \%$ & \\
\hline \multirow{4}{*}{$\begin{array}{l}\text { Academic } \\
\text { position }\end{array}$} & Assistant professor & 0 & $0.0 \%$ & 1 & $100.0 \%$ & \multirow{4}{*}{0.752} \\
\hline & Lecturer & 2 & $18.1 \%$ & 9 & $81.9 \%$ & \\
\hline & Assistant lecturer & 1 & $6.3 \%$ & 15 & $93.7 \%$ & \\
\hline & Demonstrator & 1 & $5.9 \%$ & 16 & $94.1 \%$ & \\
\hline \multirow{3}{*}{ Marital status } & Single & 1 & $14.3 \%$ & 6 & $85.7 \%$ & \multirow{3}{*}{0.648} \\
\hline & Married & 2 & $5.6 \%$ & 34 & $94.4 \%$ & \\
\hline & Widow & 0 & $0.0 \%$ & 2 & $100.0 \%$ & \\
\hline \multirow{4}{*}{$\begin{array}{l}\text { Number } \\
\text { children }\end{array}$} & None & 1 & $12.5 \%$ & 7 & $87.5 \%$ & \multirow{4}{*}{0.737} \\
\hline & $1-2$ & 1 & $4.3 \%$ & 22 & $95.7 \%$ & \\
\hline & $3-4$ & 0 & $0.0 \%$ & 3 & $100.0 \%$ & \\
\hline & 5 and more & 0 & $0.0 \%$ & 4 & $100.0 \%$ & \\
\hline \multirow{3}{*}{$\begin{array}{l}\text { Average } \\
\text { income }\end{array}$} & $2000 \mathrm{p}$ & 1 & $5.3 \%$ & 18 & $94.7 \%$ & \multirow{3}{*}{0.679} \\
\hline & $4000 \mathrm{p}$ & 1 & $5.3 \%$ & 18 & $94.7 \%$ & \\
\hline & $5000 \mathrm{p}$ and more & 1 & $14.3 \%$ & 6 & $85.7 \%$ & \\
\hline
\end{tabular}

MCP: Mont Carlo exact probability $\quad * \mathrm{P}<0.05$ (significant) 
Table 3: Relation between socio-demographic characteristics of the studied sample and performance (phase two posttest $n=45$ )

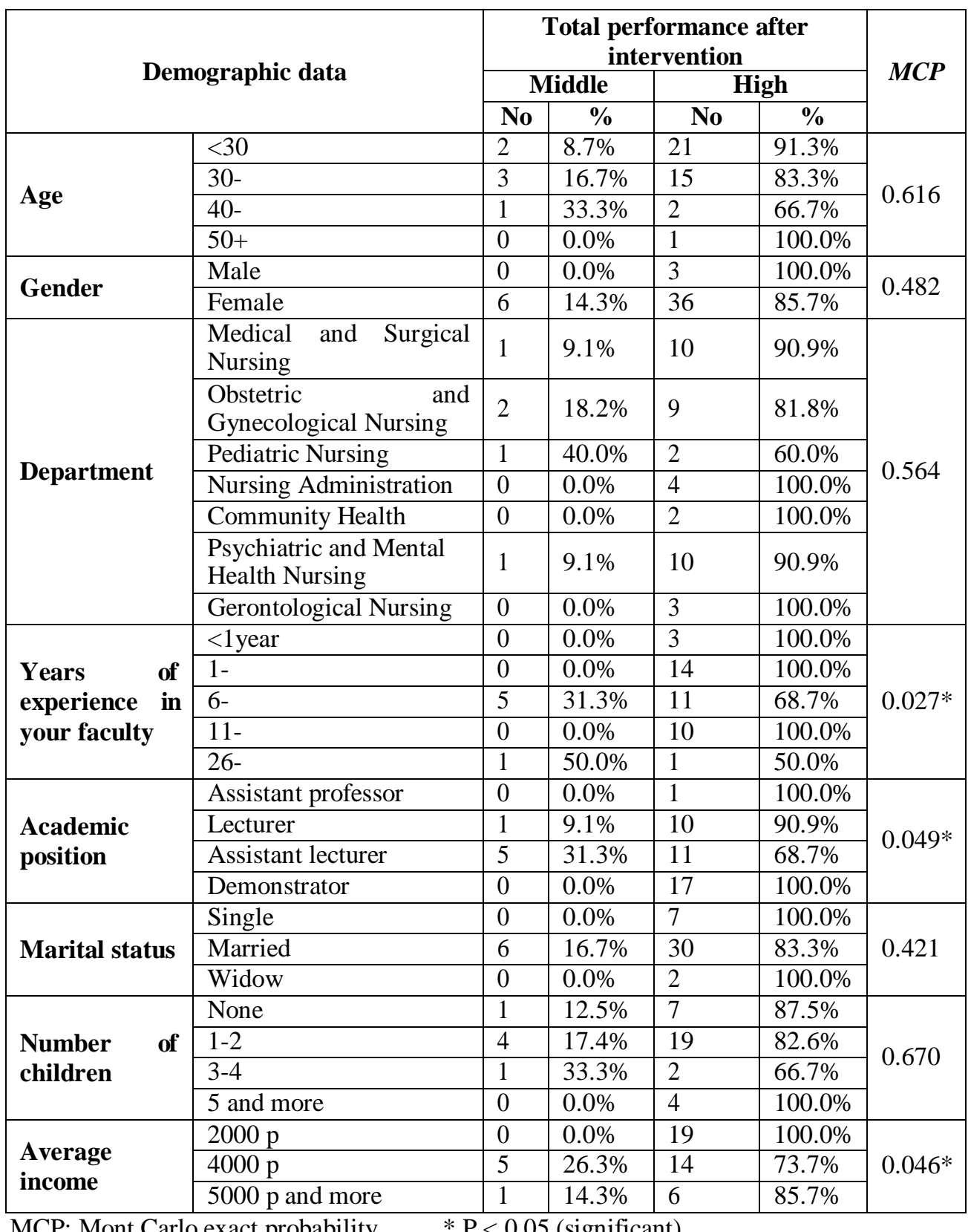

MCP: Mont Carlo exact probability

$* \mathrm{P}<0.05$ (significant) 
Table (4): Correlation between memory and performance

\begin{tabular}{|c|c|c|c|c|c|c|c|}
\hline \multirow{3}{*}{ Memory total } & \multicolumn{6}{|c|}{ Total performance } & \multirow{3}{*}{$M C P$} \\
\hline & \multicolumn{2}{|c|}{ Low } & \multicolumn{2}{|c|}{ Middle } & \multicolumn{2}{|c|}{ High } & \\
\hline & No & $\%$ & No & $\%$ & No & $\%$ & \\
\hline $\begin{array}{ll}\text { Poor } & \text { subjective } \\
\text { memory } & \\
\end{array}$ & 3 & $6.6 \%$ & 5 & $11.1 \%$ & 5 & $11.1 \%$ & \multirow{3}{*}{$0.047 *$} \\
\hline $\begin{array}{ll}\text { Fair } & \text { subjective } \\
\text { memory } & \end{array}$ & 4 & $8.8 \%$ & 6 & $13.3 \%$ & 10 & $22.2 \%$ & \\
\hline $\begin{array}{ll}\text { Good } & \text { subjective } \\
\text { memory } & \\
\end{array}$ & 0 & $0.0 \%$ & 3 & $6.6 \%$ & 9 & $20 \%$ & \\
\hline
\end{tabular}

MCP: Mont Carlo exact probability

$* \mathrm{P}<0.05$ (significant)

\section{References:}

1- Ann KM. Memory Definition \& Types of Memory. (serial on the internet).2014./(cited 2016 August 22). Available from http://www.livescience.com/43713memory.html.

2- Chiu CY. Countering Knowledge Risk in Information System Development Project. (serial on the internet).2011./(cited 2013 September 15). Available from: http://etd.lib.nsysu.edu.

3- Crook T, Feher E, Larrabee G. Assessment of Memory Complaint in Age-Associated Memory Impairment: The MAC-Q. International sychogeriatrics.1992; 4(2):176-165.

4- Helpguide.org. Improving your Memory.(serial on the internet).2014./(cited 2016 April 4). Available from: http://www.helpguide.org/articles/mem ory/how-to-improve-yourmemory.htm.

5-Hrcouncil.ca. Define performance. .(serial on the internet).2013./(cited 2016 April 23). Available at: http://webcache.googleusercontent.co m.
6-Hussein NA.Nursing Teaching Staff's Memory and its Relation to their Performance, Achievement Motivation and Meaning of Life in Zagazig University. Zagazig Nursing Journal.2013;10 ( 1): pp. 35 - 47.

7-Oermann MH. Teaching in Nursing and Role of the Educator: The Complete Guide to Best Practice in Teaching, Evaluation and Curriculum Development,2015 Springer Publishing Company.New York.P4.

8- Pottage, Claire L, Schaefer. etal.

Visual Attention and Emotional Memory: Recall of Aversive Pictures is Partially Mediated by Concurrent Task Performance.PsychINFO;2012.12(1):3 8-33.

9- Winterling D, Crook T, Salama, M. etal. A self Rating scale for Assessing Memory Loss.Psychol Aging;1986. 5(1):57-48.

10- Zinke K, Zeintl M, Rose NS, etal .Working memory training and transfer in older adults: effects of age, baseline performance, and training gains. Dev Psychol. 2014 Jan;50(1):304-15. 